\title{
Rate-Dependent Changes in Atrial Action Potential Duration After Short- Duration Rapid Atrial Pacing in Humans
}

\author{
Ichiro Watanabe, MD; Riko Masaki, MD; Kimie Ohkubo, MD; \\ Yasuo Okumura, MD; Takeshi Yamada, MD; Naohiro Oshikawa, MD; \\ Satoshi Saito, MD; Yukio Ozawa, MD; Katsuo Kanmatsuse, MD
}

\begin{abstract}
The effect of rapid atrial pacing on the rate adaptation of the atrial action potential duration was studied in humans. The right atrial monophasic action potential (RAMAP) of 5 patients was recorded before and after $30 \mathrm{~min}$ of rapid atrial pacing. The pacing cycle length (CL) was $146 \pm 9 \mathrm{~ms}$, the shortest duration at which 1:1 capture was possible. The RAMAP duration at $90 \%$ repolarization (RMAPD) was measured. CL-dependent changes in RAMAPD (CL $600 \mathrm{~ms}-$ CL $300 \mathrm{~ms}$ ) before and after rapid atrial pacing were $51.8 \pm 10.7 \mathrm{~ms}$ and $30.8 \pm$ $7.6 \mathrm{~ms}$ (p<0.05), respectively. (Circ J 2002; 66: 874-875)
\end{abstract}

Key Words: Atrial fibrillation; Electrical remodeling; Monophasic action potential

$\mathbf{E}$ xperimental studies in goats have shown that atrial fibrillation (AF) induces remodeling of the atria and that this effect is time dependent and may promote perpetuation of AF! Experimental and clinical studies on the effects of short-term rapid atrial pacing on the atrial effective refractory period (ERP) have also been reported,-4 but no previous studies have assessed the rate-dependent changes in atrial action potential duration (APD) after shortduration rapid atrial pacing in humans. The purpose of this study was to assess these changes in humans.

\section{Methods \\ Characteristics of the Study Population \\ The subjects in this study were 5 patients referred to the Nihon University Hospital for electrophysiological testing and radiofrequency catheter ablation (3 patients, manifest WPW syndrome; 1 patient, concealed Wolff-Perkinson- White (WPW) syndrome; 1 patient, atrioventricular node reentrant tachycardia; 2 men, mean age 45 \pm 16 (20-62) years $[ \pm \mathrm{SD}])$. None of the patients had a prior history of AF. \\ Electrophysiological Testing \\ Antiarrhythmic drugs, calcium-channel antagonists and $\beta$ blockers were discontinued for 5 half-lives before the electrophysiological procedure. Informed consent was obtained from the patient and the patient's family. One quadripolar electrode catheter (EP Technology Corp, Sunnyvale, CA, USA) was positioned in the right atrial appendage for rapid atrial pacing. One quadripolar catheter and one Franz catheter (both from EP Technology Corp)}

(Received March 25, 2002; revised manuscript received June 11, 2002; accepted July 3, 2002)

The Second Department of Medicine, Nihon University School of Medicine, Tokyo, Japan

Mailing address: Ichiro Watanabe, MD, The Second Department of Medicine, Nihon University School of Medicine, 30-1 Oyaguchikami, Itabashi-Ku, Tokyo 173-8610, Japan. E-mail: iwatanab@med. nihon-u.ac.jp were positioned in the high right atrium (RA) for pacing and monophasic action potential (MAP) recording, respectively5. Surface ECG leads I, II, III, $\mathrm{V}_{1}$ and $\mathrm{V}_{6}$, and the RAMAP waveform (filter: $0.05-500 \mathrm{~Hz}$ ) were recorded.

\section{Study Protocol}

The study was approved by the Human Research Committee of Nihon University Hospital and was performed after completion of the clinically indicated portion of the electrophysiological study. Autonomic blockade was achieved by infusion of atropine $(0.04 \mathrm{mg} / \mathrm{kg})$ and propranolol $(0.2 \mathrm{mg} / \mathrm{kg})$ over a period of $5 \mathrm{~min}$. RA pacing was performed at twice the late diastolic threshold. The RAMAP was measured at $90 \%$ repolarization time (RAMAPD90) at pacing CL of $600,500,400,300$, and $250 \mathrm{~ms}$ for 120 beats. RAMAPD90 was measured as the mean of the last 5 paced beats.

Rapid atrial pacing was performed at CL of $146 \pm 9 \mathrm{~ms}$ (140-160 ms), the duration at which the shortest 1:1 atrial capture was obtained at an output of $10 \mathrm{~V}$ with $2 \mathrm{~ms}$ pulse width, for $30 \mathrm{~min}$. Electrical cardioversion was performed in one patient whose AF did not spontaneously convert after $5 \mathrm{~min}$. Immediately after rapid atrial pacing or cardioversion, RAMAP measurements were repeated (Fig 1).

\section{Statistical Analysis}

All values were expressed as mean \pm SEM. The Wilcoxon signed-ranks test was used to compare the effects of rapid atrial pacing.

\section{Results}

RAMAPD90 measurements before rapid atrial pacing at pacing CL of $600,500,400,300$, and $250 \mathrm{~ms}$ were $232.8 \pm$ $13.9,226.8 \pm 13.4,216.2 \pm 11.7,181.0 \pm 9.9$, and 177.3 \pm $11.3 \mathrm{~ms}$, respectively. RAMAPD90 measurements immediately after rapid atrial pacing or cardioversion at pacing CL of $600,500,400,300$, and $250 \mathrm{~ms}$ were $221.2 \pm 12.8$, $214.6 \pm 12.7,206.6 \pm 10.3,190.4 \pm 9.2$, and $170.3 \pm 5.8 \mathrm{~ms}$, 


\section{Control}
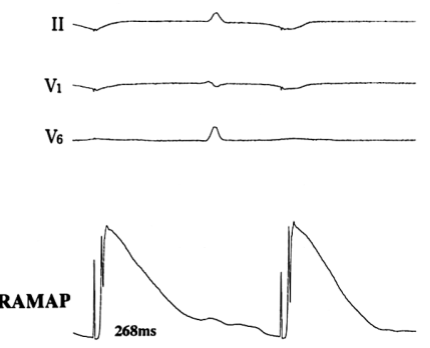

$268 \mathrm{~ms}$
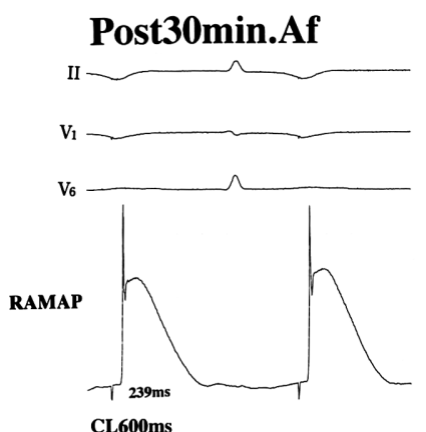

CL600ms
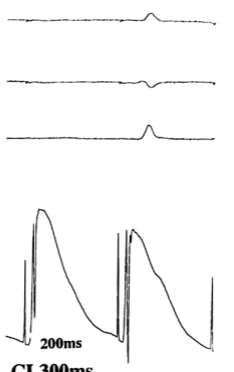

CL300ms
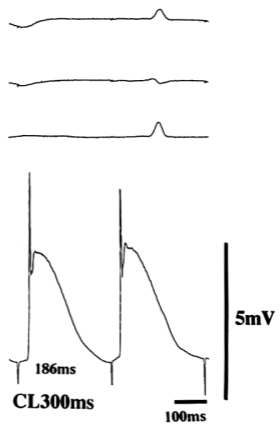

Fig 1. Right atrial monophasic action potentials recorded before (Upper panel) and after $30 \mathrm{~min}$ of rapid atrial pacing. Right atrial monophasic action potential duration (RAMAPD) at pacing cycle lengths of $600 \mathrm{~ms}$ before and after rapid atrial pacing was $268 \mathrm{~ms}$ and $239 \mathrm{~ms}$, respectively, and of $300 \mathrm{~ms}$ before and after rapid atrial pacing was $200 \mathrm{~ms}$ and $186 \mathrm{~ms}$, respectively. Note that RAMAPD after rapid atrial pacing was shortened by $29 \mathrm{~ms}$ at a pacing cycle length of $600 \mathrm{~ms}$ and by $14 \mathrm{~ms}$ at a pacing cycle length of $300 \mathrm{~ms}$. RAMAP, Right atrial monophasic action potential; CL, cycle length; AF: Atrial fibrillation.

respectively (Fig 2, left). There was no statistically significant difference in RAMAPD90 at each pacing CL between before and after rapid atrial pacing. We then calculated the rate-dependent changes in RAMAPD90 ( $\triangle$ RAMAPD90 = RAMAPD90 at pacing CL of $600 \mathrm{~ms}-$ RAMAPD90 at pacing CL of $300 \mathrm{~ms}$ ). $\triangle$ RAMAPD90 before rapid atrial pacing was $51.8 \pm 10.8 \mathrm{~ms}$ and $\triangle \mathrm{RAMAPD} 90$ after rapid atrial pacing was $30.8 \pm 7.6 \mathrm{~ms}(\mathrm{p}<0.05)$.

\section{Discussion}

In this study, $30 \mathrm{~min}$ of high atrial pacing resulted in a decrease in the rate-dependent changes in RAMAPD90. This phenomenon was observed despite autonomic blockade. To our knowledge, this is the first study to report electrical remodeling of the atrial MAP by short-term rapid atrial pacing in humans. Goette et al reported that ERP shortening in the RA appendage was $24 \pm 2 \mathrm{~ms} / \mathrm{h}$ in the canine heart during the first $30 \mathrm{~min}$ of high-frequency pacing, and Lee et al also reported MAPD and ERP shortening in the canine right atrium after high-rate atrial pacing at 800 beats/min for $30 \mathrm{~min}$ were $24 \mathrm{~ms}$ and $18 \mathrm{~ms}$, respectively4 Daoud et al reported in humans that atrial ERP decreased by $31 \mathrm{~ms}$ at a basic CL of $350 \mathrm{~ms}$ and by $25 \mathrm{~ms}$ at a basic CL of $500 \mathrm{~ms}$ after spontaneous conversion of $\mathrm{AF}$ lasting $7.3 \pm 1.9 \mathrm{~min}$ and that the post-AF ERP returned to the pre-AF value after a mean of $8.4 \pm 0.3 \mathrm{~min}$ ? Yu et al also reported that the atrial ERP decreased by $30 \mathrm{~ms}$ at a basic
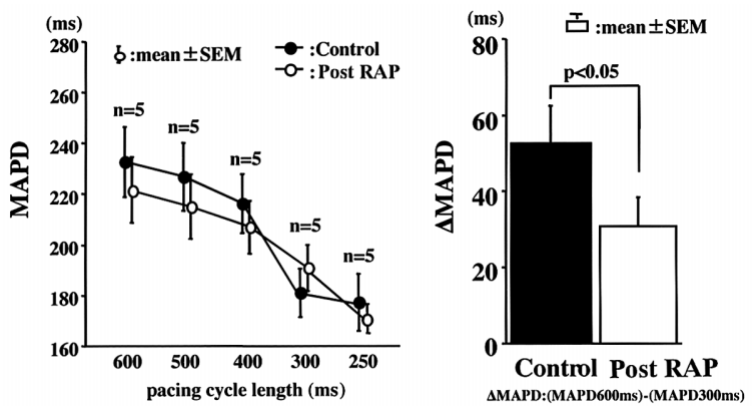

Fig 2. Rate-dependent changes in right atrial monophasic action potential duration before and after 30 min of rapid atrial pacing. Note that the rate-dependent decrease in the right atrial monophasic action potential duration was diminished after rapid atrial pacing. MAPD, monophasic action potential duration; RAP, rapid atrial pacing.

CL of $500 \mathrm{~ms}$ after $10.4 \pm 1.0 \mathrm{~min}$ of pacing-induced AF6 Our results are consistent with those of previous studies showing a decrease in APD and ERP after short-term rapid atrial pacing. Furthermore, our results demonstrated that the rate-dependent changes in RAMAPD90 decreased after short-term rapid atrial pacing because of a slight decrease in RAMAPD at a pacing CL of $600 \mathrm{~ms}$ and a slight increase in RAMAPD at a pacing CL of $300 \mathrm{~ms}$. Van der Velden et al reported that RAMAPD was rather increased at shorter pacing CL after chronic atrial fibrillation in the goat? Thus, it is possible that the decrease in frequency-dependent changes in RAMAPD following short-term rapid atrial pacing results from not only a decease in RAMAPD at a longer pacing CL but also a decrease in the extent of RAMAPD shortening or ratheran increase in RAMAPD at a shorter pacing CL compared with the control. Finally, Kim et al recently reported the importance of recording atrial MAP to assess atrial action potential kinetics in human chronic AF?

\section{References}

1. Wijffels MC, Kirchof CJ, Dorland R, Allessie MA. Atrial fibrillation begets atrial fibrillation: A study in awake chronically instrumented goats. Circulation 1995; 92: 1954-1968.

2. Goette A, Honeycutt C, Langberg JJ. Electrical remodeling in atrial fibrillation: Time course and mechanisms. Circulation 1996; 94: $2968-2979$

3. Daoud EG, Bogun F, Goyal R, Harvey M, Man KC, Strickberger SA, et al. Effect of atrial fibrillation on atrial refractoriness in humans. Circulation 1996; 94: 1600-1606.

4. Lee SH, Chen SA, Yu WC, Cheng JJ, Kaun P, Huang R, et al. Changes of atrial refractory period after short duration of rapid atrial pacing: Regional differences and possible mechanisms. Pacing Clin Electrophysiol 1999; 22(Part 1): 927-934.

5. Sekiya J, Ohnishi Y, Inoue T, Yokoyama M. Monophasic action potentials of the right atrium in patients with paroxysmal atrial fibrillation. Jpn Circ J 2001; 65: 893-896.

6. Yu W, Chen SA, Lee SH, Tai CT, Feng AN, Kuo BI, et al. Tachycardia-induced change of atrial refractory period in humans: Rate dependency and effects of antiarrhythmic drugs. Circulation 1998; 97: 2331-2337.

7. Van der Velden HMW, van der Zee L, Wijffels MCEF, van Leuven C, Dorland R, Vos MA et al. Atrial fibrillation in the goat induces changes in monophasic action potential and mRNA expression of ion channels involved in repolarization. $J$ Cardiovasc Electrophysiol 2000; 11: $1262-1269$.

8. Kim BS, Kim YH, Hwang GS, Pak HN, Lee SC, Shim WJ et al. Action potential duration restitution kinetics in human atrial fibrillation. J Am Coll Cardiol 2002; 39: 1329-1336. 